\title{
PEMBERDAYAAN KADER POSYANDU LANSIA DALAM UPAYA PENCEGAHAN HIPERTENSI DAN KOMPLIKASINYA
}

\author{
Ayu Dewi Nastiti ${ }^{*}$, Erik Kusuma ${ }^{2}$, R.A Helda Puspitasari ${ }^{3}$ \\ Prodi D3 Keperawatan Fakultas Keperawatan \\ Universitas Jember Kampus Kota Pasuruan
}

Email Korespondensi: ayudewi.akper@unej.ac.id

\author{
Disubmit: 11 Oktober 2021 Diterima: 4 Desember $2021 \quad$ Diterbitkan: 01 Januari 2022 \\ DOI: https://doi.org/10.33024/jkpm.v1i1.5280
}

\begin{abstract}
ABSTRAK
Hipertensi di Indonesia memerlukan perhatian yang serius karena merupakan penyebab kematian nomor 3 setelah stroke dan tuberculosis. Seiring dengan semakin meningkatnya angka penderita hipertensi di Indonesia, pemerintah merumuskan berbagai kebijakan pelayanan kesehatan untuk lansia agar derajat dan mutu kesehatan lansia penderita hipertensi dapat meningkat. Salah satunya yaitu dengan mencanangkan pelayanan kesehatan pada lansia melalui beberapa jenjang. Pelayanan di tingkat masyarakat dilakukan oleh Posyandu Lansia. Uraian situasi di atas merupakan dasar mengapa perlu dilakukan pemberdayaan kader posyandu lansia untuk pencegahan hipertensi dan komplikasinya di Kecamatan Purwosari Kabupaten Pasuruan. Bentuk kegiatan pengabdian masyarakat ini berupa pemberian edukasi tentang hipertensi dan komplikasinya serta, memberikan pelatihan pemerikasaan tekanan darah bagi kader. Subjek dalam kegiatan ini adalah seluruh kader kesehatan di wilayah Kecamatan Purwosari. Lokasi ini dipilih mengingat kasus hipertensi di wilayah ini masih cukup tinggi. Kegiatan pengabdian ini mendapatkan sambutan hangat dari peserta. Hal ini terbukti dengan banyaknya peserta yang aktif dalam diskusi dan mengajukan pertanyaan. Setelah sesi diskusi pemateri malakukan post test secara lisan kepada peserta, dalam post test yang dilakukan $100 \%$ peserta mampu menjawab pertanyaan yang disampaikan oleh pemateri dengan benar. Kesimpulan yang bisa ditarik dari kegiatan ini seluruh peserta cukup aktif dalam kegiatan ini dan tidak meninggalkan tempat sampai acara selesai. Upaya peningkatan pengetahuan masyarakat tentang penyakit hipertensi dapat lebih maksimal setelah diadakan kegiatan ini diukur dengan hasil apersepsi dan evaluasi.
\end{abstract}

Kata Kunci: Pemberdayaan, Kader, Hipertensi

\begin{abstract}
Hypertension in Indonesia requires serious attention because it is the $3^{\text {rd }}$ cause of death after stroke and tuberculosis iln line with the increasing number of hypertension sufferers in Indonesia, the government has formulated various health service policies for the elderly so that the degree and quality of health of elderly people with hypertension can increase. One of them is by implementing health services for the elderly through several levels. Services at the community level are provided by the Elderly Posyandu. The description of the situation above was the basis of why it is necessary to empower elderly Posyandu cadres for the prevention of hypertension and its complications in Purwosari District, Pasuruan Regency. The form of this community service activity was in the form of providing education about hypertension and its complications as well as providing training in blood pressure checks for cadres.
\end{abstract}


The subjects in this activity were all Health Cadres in the Purwosari District area. This location was chosen considering that there were still many cases of hypertension in this region. This service activity received a warm welcome from the participants. This is evidenced by the large number of participants who are active in the discussion and asking questions. After the discussion session the speaker performs a post test orally to the participants, in the post test $100 \%$ participants were able to answer the questions presented by the speaker correctly. The conclusion that can be drawn from this activity was that all participants were quite active in this activity and do not leave the venue until the event was over. Efforts to increase public knowledge about hypertension can be maximized after this activity was measured by the results of apperception and evaluation.

Keywords: Empowerment, Cadres, Hypertension

\section{PENDAHULUAN}

Pembangunan kesehatan Indonesia diarahkan guna mencapai pemecahan masalah kesehatan untuk hidup sehat bagi setiap penduduk agar dapat mewujudkan derajat kesehatan yang optimal. Masalah kesehatan dapat dipengaruhi oleh pola hidup, pola makan, lingkungan kerja, olahraga dan stres. Perubahan gaya hidup terutama di kota-kota besar, menyebabkan meningkatnya prevalensi penyakit degeneratif, seperti penyakit jantung, hipertensi, hiperlipidemia, diabetes melitus (DM) dan lain-lain.

Hipertensi adalah peningkatan tekanan darah sistolik sedikitnya $140 \mathrm{mmHg}$ atau tekanan diastolik sedikitnya $90 \mathrm{mmHg}$ (Price \& Wilson, 2006). Menurut World Health Organization, batas tekanan darah yang masih dianggap normal yaitu $140 / 90 \mathrm{mmHg}$, sedangkan tekanan darah di atas $160 / 95 \mathrm{mmHg}$ dinyatakan sebagai hipertensi. Hipertensi dapat menyebabkan banyak komplikasi. Komplikasi-komplikasi akibat hipertensi diantaranya adalah stroke, gagal jantung, gangguan ginjal dan gangguan penglihatan (Price \& Wilson, 2006). Hipertensi sering terjadi pada lansia karena pada lansia terjadi perubahan struktural dan fungsional pada sistem pembuluh perifer yang mengakibatkan penuruan distensi dan daya regang pembuluh darah ${ }^{\mathrm{ii}}$. Perubahan-perubahan yang sering terjadi pada lansia diantaranya adalah hilangnya elastisitias jaringan ikat, aterosklerosis, penurunan relaksasi otot polos pembuluh darah ${ }^{\mathrm{iii}}$. Gangguangangguan pembuluh darah ini akan mengakibatkan aorta dan arteri menjadi berkurang kemampuannya dalam mengakomodasi volume darah dari jantung, sehingga pada akhirnya dapat mengakibatkan penurunan curah jantung dan peningkatan tahanan periferiv .

Hipertensi di Indonesia memerlukan perhatian yang serius karena merupakan penyebab kematian nomor 3 setelah stroke dan tuberkulosis ${ }^{\vee}$. Tingkat kematiannya juga mencapai $6,7 \%$ dari populasi kematian pada semua umur di Indonesia (Depkes RI, 2010). Seiring dengan semakin meningkatnya angka penderita hipertensi di Indonesia, pemerintah merumuskan berbagai kebijakan pelayanan kesehatan untuk lansia agar derajat dan mutu kesehatan lansia penderita hipertensi dapat meningkat ${ }^{\mathrm{vi}}$. Salah satunya yaitu dengan mencanangkan pelayanan kesehatan pada lansia melalui beberapa jenjang ${ }^{\text {vii. }}$. Pelayanan di tingkat masyarakat dilakukan oleh Posyandu Lansia. Posyandu lansia adalah suatu pos pelayanan terpadu yang ditujukan untuk masyarakat lanjut usia di suatu wilayah tertentu yang sudah disepakati, yang digerakkan oleh masyarakat dimana mereka bisa mendapatkan pelayanan kesehatan ${ }^{\text {viii }}$. 
Uraian situasi di atas merupakan dasar mengapa perlu dilakukan pemberdayaan kader posyandu lansia untuk pencegahan hipertensi dan komplikasinya di Kecamatan Purwosari Kabupaten Pasuruan. Bentuk kegiatan pengabdian masyarakat ini berupa pemberian edukasi tentang hipertensi dan komplikasinya serta, memberikan pelatihan pemerikasaan tekanan darah bagi kader.

\section{MASALAH}

Kader Posyandu Lansia merupakan masyarakat terpilih yang diharapkan mampu untuk membantu meperbaiki derajad kesehatan warga di sekitarnya. Peningkatan pengetahuan dan ketrampilan kader Posyandu sangat penting dalam menunjang keberhasilan upaya peningkatan kualitas kesehatan warga masyarakat. Berdasarkan analisa situasi, permasalahan yang dapat dirumuskan antara lain:

1. Pengetahuan masyarakat mengenai penyakit Hipertensi, pencegahan, dan penatalaksanannya secara nonfarmakologis atau perubahan gaya hidup, serta penggunaan obat Hipertensi yang rasional masih rendah.

2. Rendahnya pengetahuan tentang pola makan (life Style) warga untuk mengendalikan kadar tekanan darah.

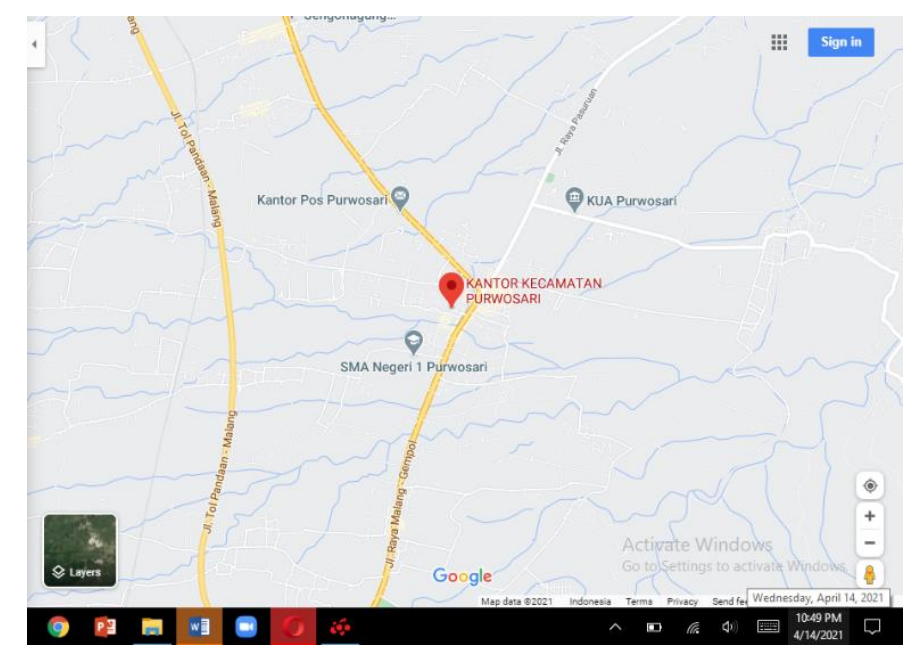

Gambar 1. Kecamatan Purwosari Kabupaten Pasuruan

\section{METODE}

Subjek dalam kegiatan ini adalah seluruh Kader Kesehatan di wilayah Kecamatan Purwosari. Lokasi ini dipilih mengingat kasus Hipertensi di Wilyah ini masih banyak. Tahap persiapan dilakukan dengan melakukan koordinasi dengan Pemerintah Kecamatan setempat terkait dengan akan diselenggrakannya kegiatan pengabdian ini, mengidentifikasi kebutuhan sumber daya selama kegiatan, dan mempersiapkan segala kebutuhan kegiatan dengan dibantu oleh mahasiswa Prodi D3 Keperawatan Unej Kampus Kota Pasuruan.

Tahap Implementasi yaitu memilih strategi komunikasi yang efektif untuk pelaksaaan kegiatan, teknik ceramah dipilih karena dianggap paling efektif untuk meningkatkan pengetahuan masyarakat, selain itu juga digunakan teknik diskusi dimana diharapkan masyarakat bisa saling bertukar pikiran. Selain itu terdapat juga demonstrasi terkait cara pemeriksaan tekanan darah secara benar kepada seluruh peserta. Sebelum dimulai kegiatan terlebih 
dahulu dijelaskan maksud dan tujuan dilakukan kegiatan. Kegiatan pelatihan ini dibuka oleh Bapak Camat dilanjutkan dengan perkenalan dan penyampaian materi. Dalam pelaksanaan kegiatan ini menggunakan media LCD untuk pemaparan teori terkait hipertensi terutama tentang pencegahan dan komplikasinya kemudian dilanjutkan dengan sesi diskusi, dan diakhiri dengan pelatihan teknik pemeriksaan tekanan darah secara benar.

\section{HASIL DAN PEMBAHASAN}

Kegiatan ini berlangsung selama 3 bulan mulai dari proses persiapan perencanaan proposal sampai dengan pelaksanaannya. Puncak pelaksanaan kegiatan dilaksanakan pada tanggal 8 Januari 2020, dimana dalam kegiatan ini diawali dengan penyampaian materi oleh narasumber yaitu 2 orang dosen dari Prodi DIII Keperawatan Fakultas Keperawatan Universitas Jember Kampus Kota Pasuruan materi yang disampaikan ditekankan pada pencegahan komplikasi hipertensi. Selama berlangsungnya kegiatan, peserta terlihat antusias mendengarkan dan aktif berdiskusi. Pada awal penyampaian materi, pemateri meminta peserta untuk menyampaikan pengetahuannya tentang hipertensi. Setelah materi disampaikan, dilakukan pelatihan cara memeriksa tekanan darah secara benar. Kegiatan pengabdian ini mendapatkan sambutan hangat dari peserta. Hal ini terbukti dengan banyaknya peserta yang aktif dalam diskusi dan mengajukan pertanyaan. Setelah sesi diskusi pemateri malakukan post tes secara lisan kepada peserta, dalam post tes yang dilakukan peserta mampu menjawab pertanyaan yang disampaikan oleh pemateri dengan benar.

Seperti yang disampaikan oleh Shalahudin Iwan (2021) dimana metode ceramah sangat efektif untuk mempermudah peserta dalam memahami isi dan

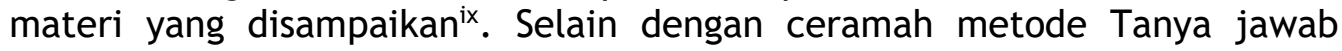
merupakan salah satu usaha untuk menyingkirkan rintangan selama proses ceramah.

Efektifitas metode yang digunakan oleh pemateri yaitu ceramah dan diskusi cukup terlihat, terbukti dengan sebagian besar peserta (90\%) memahami dan mengerti tentang materi yang disampaikan. Peserta senang dengan penyuluhan ini, hal ini terbukti dengan banyaknya peserta yang aktif dalam diskusi dan mengajukan pertanyaan serta antusias ketika pelaksanaan diskusi Berikut gambar pelaksanaan kegiatan:

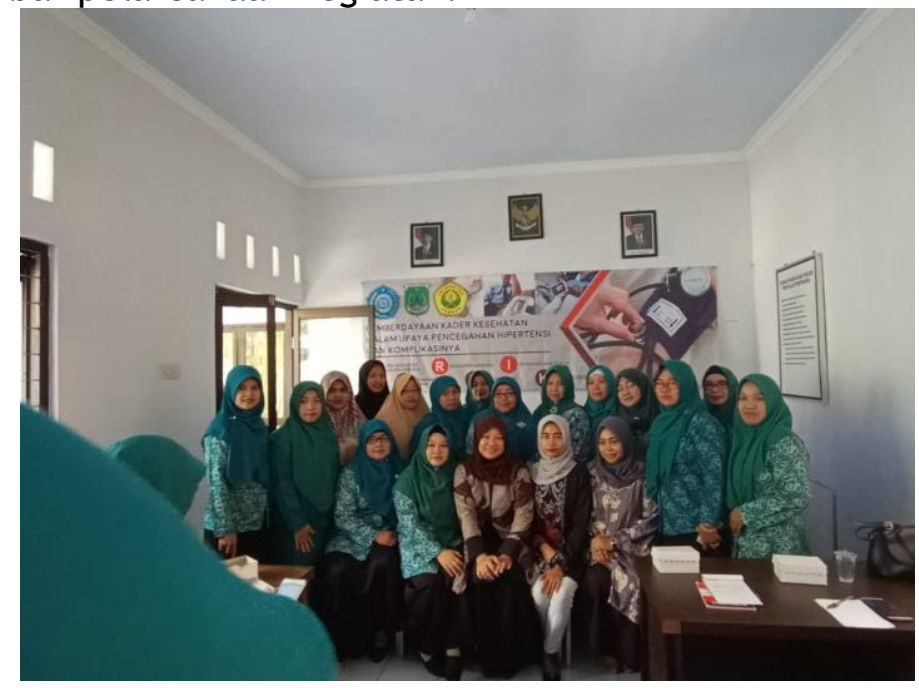

Gambar 2. Foto Bersama Peserta 


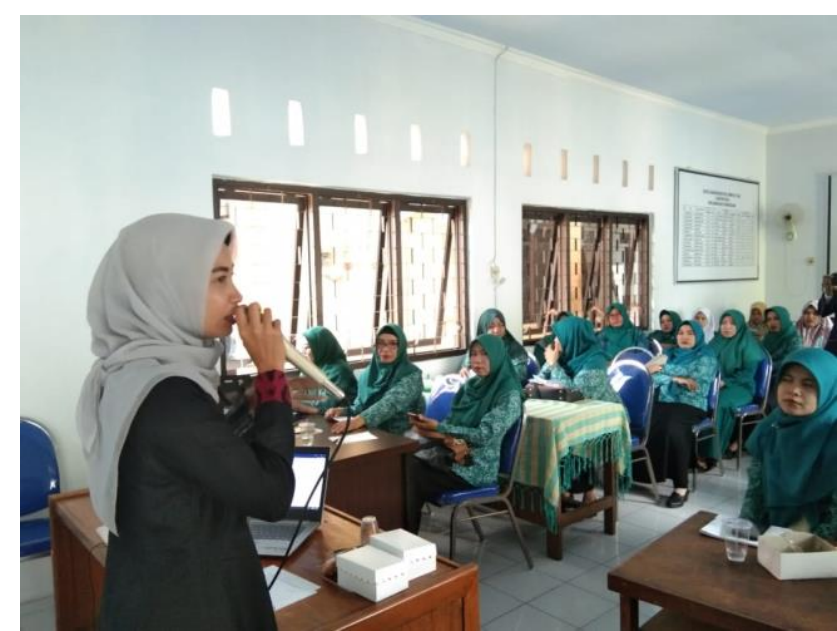

Gambar 3. Foto Narasumber Saat Menyampaikan Materi

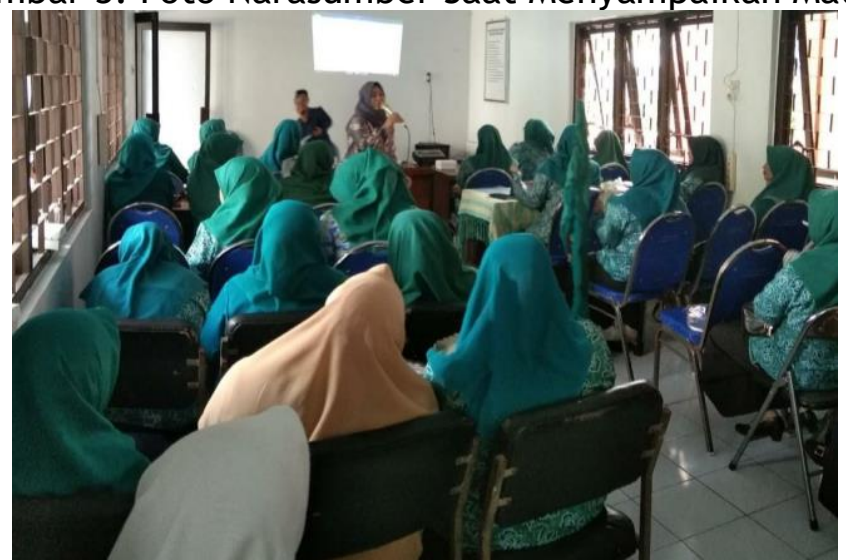

Gambar 4. Foto Narasumber saat menyampaikan Materi

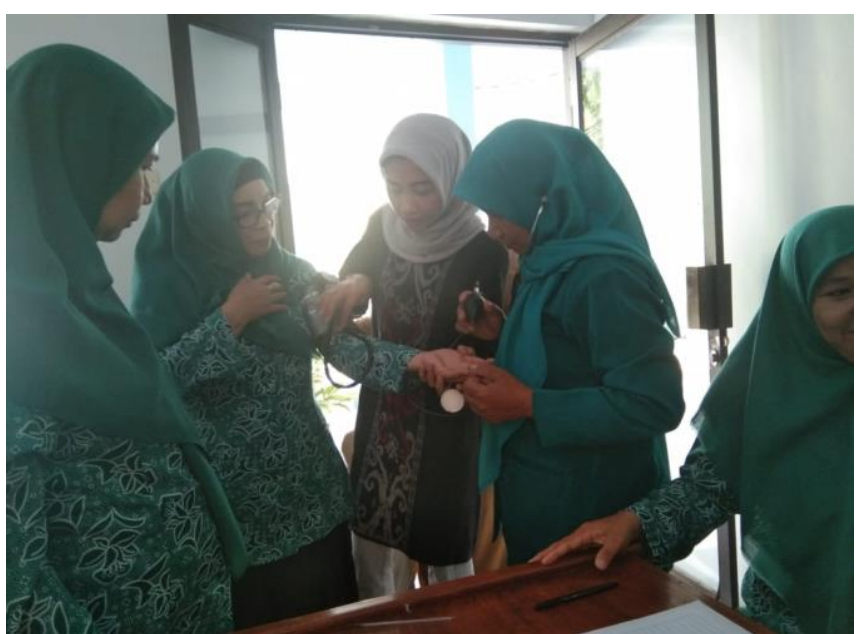

Gambar 5. Foto Pelatihan cara pemeriksaan tekanan darah

\section{KESIMPULAN}

Kesimpulan yang bisa ditarik dari kegiatan ini seluruh peserta cukup aktif dalam kegiatan ini dan tidak meninggalkan tempat sampai acara selesai. Upaya peningkatan pengetahuan masyarakat tentang penyakit Hipertensi dapat lebih maksimal setelah diadakan kegiatan ini di ukur dengan hasil apersepsi dan evaluasi. 


\section{DAFTAR PUSTAKA}

Rahajeng E, Tuminah S. (2009). Prevalensi Hipertensi dan Determinannya di Indonesia. Jakarta: Pusat Penelitian Biomedis dan Farmasi Badan Penelitian Kesehatan Departemen Kesehatan RI.

Anggriyana, T, W., \& Proverawati, W. (2015). Senam kesehatan. Yogyakarta: Muha Medika.

Lin, G. H., Chang, W. C., Chen, K. J., Tsai, C. C., Hu, S. Y., \& Chen, L. L. (2016).Effectiveness of Acupressure on the Taichong Acupoint in Lowering Blood Pressure in Patients with Hypertension: A Randomized Clinical Trial. Evidence-Based Complementary and Alternative Medicine, 2016(1549658), 1-9. doi: 10.1155/2016/1549658.

Price, S. A., \& Wilson, L. M. (2006). Patofisiologi konsep klinis proses-proses penyakit (Edisi 4). Jakarta: EGC.

Rahajeng E, Tuminah S. (2009). Prevalensi Hipertensi dan Determinannya di Indonesia. Jakarta: Pusat Penelitian Biomedis dan Farmasi Badan Penelitian Kesehatan Departemen Kesehatan RI.

Ricky, Riyanto Iksan,dkk. (2020). Upaya Pencegahan Stroke Pada Lansia Dengan Hipertnesi Melalui Penyuluhan Kesehatan Tentang Hipertensi. Jurnal Kreativitas Pengabdian Kepada Masyarakat (PKM) Volume 3 Nomor 2 https: //doi.org/10.33024/jkpm.v3i2.3197.

Profil Kesehatan Provinsi Jawa Tengah. (2012). Profil kesehatan Provinsi Jawa Tengah.Retrieved July 17, 2017 from http://pppl.depkes.go.id.

Saputri, Romadhiyana Kisno \& Hadiyatul Lilfitriyani. (2020). Pelatihan Kader Antihipertensi Sebagai Upaya Menurunkan Angka Hipertensi Di Kabupaten Bojonegoro. Jurnal Kreativitas Pengabdian Kepada Masyarakat (PKM) Volume 3 Nomor 2, DOI: https://doi.org/10.33024/jkpm.v3i2.2927

Shalahuddin, I., Rosidin, U., \& Purnama, D. (2021). Edukasi Pada Masyarakat Desa Mekarbakti Kecamatan Pamulihan Kabupaten Sumedang Tentang Pentingnya Upaya-Upaya Pencegahan Penularan Penyakit Covid-19. Jurnal Kreativitas Pengabdian Kepada Masyarakat (PKM), 4 (1), 1 9, https://doi.org/10.33024/jkpm.v4i1.3594. 